\title{
ASPECTOS EPIDEMIOLÓGICOS DAS INFECÇÕES POR ROTAVÍRUS NO DISTRITO FEDERAL, BRASIL
}

\author{
José Marcus Sócrates Teixeira, Rosane Braga de Figueiredo, \\ Helena Maria Pereira dos Santos, Maria Neusa Ribeiro Ferreira \\ e Geni Neumann Noceti de Lima Câmara.
}

\begin{abstract}
Rotavirus foram pesquisados em 607 amostras fecais de crianças de até 6 anos de idade com quadros de diarréia aguda, no período de maio de 1986 a abril de 1990. Foi utilizada a técnica de eletroforese em gel de poliacrilamida (PAGE), sendo os rotavírus detectados em 123 amostras $(20,27 \%)$ das quais $107(87,00 \%)$ apresentaram perfil eletroforéticolongo, compatível com o subgrupo II. Os rotavirus não foram encontrados no grupo controle constituido de crianças sadias, sendo porém detectados em $7,80 \%$ das crianças internadas por outras causas que não diarréia aguda. A maioria das crianças positivas para rotavírus encontrava-se na faixa etária de 6 a 24 meses $(73,98 \%$ ). A média de positividade nos meses chuvosos (outubro a abril) foi igual a 9,60\% e no periodo seco, 34,48\% com picos que variaram entre 53,17 e 73,27\% nos meses de junho e julho, os mais frios do ano.
\end{abstract}

Palavras-chaves: Rotavírus. Diarréia aguda infantil. Epidemiologia.

As diarréias agudas infantis constituem importante problema de saúde pública particularmente em países em desenvolvimento, onde são responsáveis por altas taxas de morbidade e mortalidade ${ }^{1826}$.

Têm sido identificados como agentes etiológicos das diarréias agudas infantis, parasitas intestinais, bactérias e vínus ${ }^{816}$, sendo os rotavírus considerados atualmente os maiores responsáveis por esses quadros em crianças, tanto em países de clima temperado ${ }^{11}{ }^{12}$ como em países tropicais ${ }^{729}$.

A incidência dos rotavírus é maior no grupo etário de zero a seis anos, particularmente em crianças menores de um ano ${ }^{5612}$.

Em países de clima temperado, a frequência dos rotavírus é significativamente maior durante os meses de inverno ${ }^{11}{ }^{12}$. Ao contrário, em países tropicais não existe um padrão epidemiológico

\footnotetext{
Núcleo de Virologia, Instituto de Saúde do Distrito Federal, Brasília, DF.

Suporte financeiro: CNPq e FINEP.

Endereço para correspondência: Dr. José Marcus Sócrates Teixeira, Núcleo de Virologia, Instituto de Saúde do Distrito Federal, SGAN 601 lotes O/P, 70830 Brasília, DF.

Recebido para publicação em 19/08/91.
}

uniforme, tendo sido identificadas diferenças de um país para o outro. No Equador, as maiores frequências ocorrem durante os meses mais secos ${ }^{31}$. Na Venezuela, os rotavírus foram detectados durante todo o ano, com um pico nos meses mais frios ${ }^{32}$. No Brasil, trabalhos realizados em diferentes regiões mostraram diferenças nas frequências de gastroenterites por rotavírus em função da época do ano. $\mathrm{Na}$ cidade do Rio de Janeiro, os maiores índices de infecções ocorreram durante os meses do outono e do inverno ${ }^{1}$; em Porto Alegre, nos meses de verãos; em Belém, onde a temperatura e a umidade relativa do ar não variam muito durante $o$ ano, não foi detectada diferença sazonal significativa ${ }^{16}$; no nordeste, as maiores frequências foram detectadas no período mais seco do ano?.

O clima do Distrito Federal é caracterizado basicamente por duas estações: uma chuvosa, de outubro a abril, e uma seca, de maio a setembro, quando a precipitação pluviométrica é extremamente baixa e a umidade do ar atinge valores que preocupam as autoridades de saúde locais.

Tendo-se em conta a existência de poucos dados sobre as gastroenterites associadas a rotavírus no Distrito Federal e a peculiaridade do clima da região, julgamos importante o estudo de alguns aspectos epidemiológicos dessas infecções. 
Teixeira JMS, Figueiredo RB, Santos HMP, Ferreira MNR, Câmara GNNL. Aspectos epidemiológicos das infecções por rotavirus no Distrito Federal, Brasil. Revista da Sociedade Brasileira de Medicina Tropical 24:223230, out-dez, 1991

\section{MATERIAL E MÉTODOS}

Foram analisadas 607 amostras de fezes de crianças com diarréia aguda, a maior parte proveniente de familias de baixa renda do Distrito Federal, durante o período de maio de 1986 a abril de 1990. As crianças foram incluídas no estudo segundo os seguintes critérios:

I. faixa etária entre 0 e 6 anos;

II. diarréia de início súbito com fezes líquidas ou pastosas;

III. frequência aumentada de evacuações diárias;

IV. quadro diarréico com até 10 dias de duração;

V. quadro severo o suficiente para requerer a procura do setor de emergência de dois hospitais públicos do Distrito Federal.

Dois grupos foram utilizados como controle. $O$ primeiro composto por 96 crianças sadias, da mesma faixa etária e condição social do grupo doente. As amostras desse grupo foram colhidas de casa em casa, em Sobradinho, cidade satélite de Brasília, onde fica situado um dos hospitais envolvidos no trabalho. O segundo grupo, também com características semelhantes ao grupo doente, era composto por 127 crianças que deram entrada no setor de emergência do Hospital Regional de Sobradinho, com outras manifestações clínicas que não diarréia aguda.

Uma vez colhidas, as amostras foram congeladas a $20^{\circ} \mathrm{C}$ até serem processadas.

Para o preparo das suspensões fecais, as amostras foram diluídas a $10 \%$ em solução salina tamponada (PBS), $\mathrm{pH} \mathrm{7,2} \mathrm{e} \mathrm{clarificadas} \mathrm{por} \mathrm{centrifugação} \mathrm{a}$ $3000 \mathrm{rpm}$ por 15 minutos.

Todas as amostras foram analisadas através da técnica de eletroforese em gel de poliacrilamida (PAGE). Um estudo comparativo entre as técnicas de PAGE e ensaio imunoenzimático para rotavírus e adenovírus (EIARA) foi realizado, analisando-se 303 amostras através de ambas as técnicas.

Para a técnica de PAGE as suspensões fecais foram tratadas com dodecil-sulfato de sódio (SDS) a $10 \%$ durante 30 minutos a $37^{\circ} \mathrm{C}$, seguidas de desproteinização através de extração com fenol clorofórmico (1:1) e precipitação da fase aquosa com etanol, segundo descrição de Pereira e col$^{22}$. A dissociação do precipitado foi feita com mistu. dissociante (tampão TRIS HC1 0,625M; pH 6,8; uréia 5M; SDS 3\%; azul de bromofenol 0,01\%).

Para a eletroforese, foi utilizada a técnica de Laemmli ${ }^{13}$ modificada por Pereira e $\mathrm{col}^{22}$. O gel separador tinha uma concentração constante de $7,5 \%$ de acrilamida, enquanto que o gel concentrador de $3 \%$. A coloração do gel foi feita através da impregnação pela prata, segundo descrição de Boulikas e Hancock ${ }^{2}$. A técnica de EIARA foi realizada de acordo com a descrição de Pereira e $\mathrm{col}^{21}$.

Os métodos estatísticos utilizados foram:

I. Qui-quadrado com correção de continuidade de Yates;

II. correlação linear simples;

III. regressão linear múltipla.

Nos métodos empregados, para a hipótese nula foi usado o nível de significância $\alpha=0,05$.

\section{RESULTADOS}

Os rotavírus foram identificados em 123 $(20,27 \%)$ das 607 amostras fecais de crianças com quadro de diarréia aguda. A Figura 1 mostra a correlação entre a precipitação pluviométrica e a frequência de rotavirus. Durante os quatro anos de estudo os mais altos índices foram identificados sempre entre maio e setembro, período de baixa pluviosidade.

As frequências mensais de rotavírus variaram de 0 a $73,27 \%$ em 1986,0 a $57,12 \%$ em 1987,0 a $69,02 \%$ em 1988 e 0 a $53,17 \%$ em 1989. Esses picos ocorreram sempre nos meses de junho e julho, que se caracterizam por apresentar, além de baixa pluviosidade, as mais baixas temperaturas registradas.

A análise do genoma dos rotavírus detectados através da técnica de PAGE revelou que $87,00 \%$ dos vírus tinham perfil eletroforético longo, compatível com o subgrupo II. Treze amostras $(10,57 \%)$ apresentaram perfil curto característico do subgrupo I (Tabela 1). Através da classificação de Lourenço e $\mathrm{col}^{17}$, foi possível detectar 23 diferentes tipos eletroforéticos, com predominância dos tipos 
Teixeira JMS, Figueiredo RB, Santos HMP, Ferreira MNR, Câmara GNNL. Aspectos epidemiológicos das infeç̧ões por rotavirus no Distrito Federal, Brasil. Revista da Sociedade Brasileira de Medicina Tropical 24:223230, out-dez, 1991

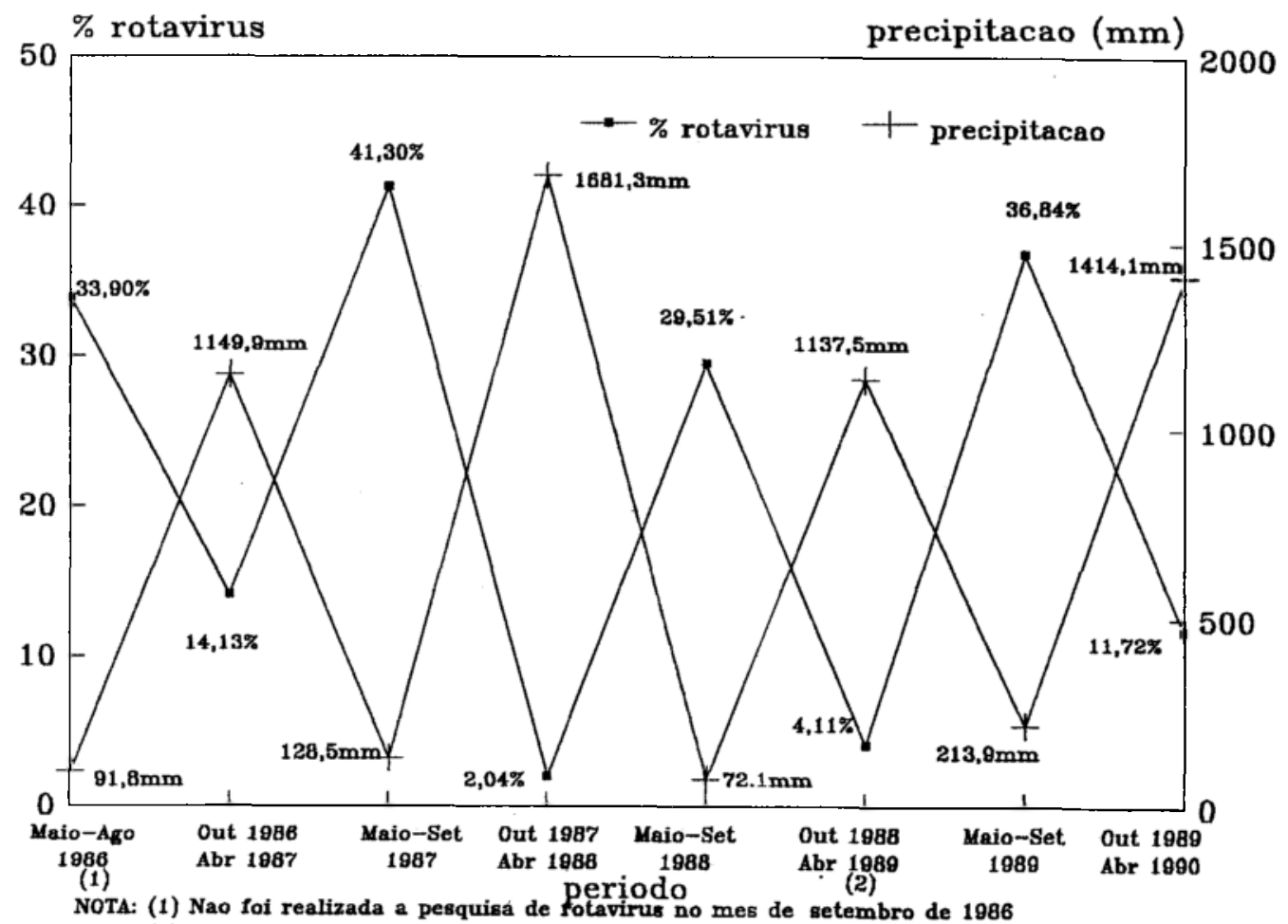

(2) Nao foi realizada a pesquisa de rotavirus no mes de dezembro de 1988.

Figura 1 - Percentual de rotavírus e preciptação acumulada (mm) - maio de 1986 a abril de 1990.

baba $(39,62 \%)$ e cbba $(25,83 \%)$ (Figura 2$)$.

A distribuição dos casos positivos por faixa etária mostrou que os rotavírus foram detectados em todas as faixas estudadas, havendo maior índice de infecção nas faixas de 12 a 24 meses $(30,59 \%)$ e de 6 a 12 meses (24,87\%). A positividade diminuiu significativamente nas faixas etárias de 0 a 6 meses $(10,77 \%)$ e entre crianças maiores de dois anos (6,49\%) (Tabela 2).

A distribuição dos casos positivos para rotavírus segundo a presença, nas residências, de água $\mathrm{e}$ esgoto ligados à rede pública, mostrou que $68,28 \%$ das casas eram servidas de água e que $60,97 \%$ possuíam esgotos ligados à rede.

Os rotavírus não foram detectados nas amostras do grupo controle constituído de crianças sadias. No grupo de crianças internadas com outras manifestações clínicas diferentes de diarréia aguda, houve uma positividade de $7,80 \%$.
Tabela 1 - Classificação dos rotavírus detectados em Brasilia, Distrito Federal, segundo o subgrupo - maio de 1986 a abril de 1990.

Subgrupo

Número

$\%$

Subgrupo II

107

87,00

Subgrupo I

13

10,57

Não Classificados

3

Total

123

100,00 
Teixeira JMS, Figueiredo RB, Santos HMP, Ferreira MNR, Câmara GNNL. Aspectos epidemiológicos das infecções por rotavírus no Distrito Federal, Brasil. Revista da Sociedade Brasileira de Medicina Tropical 24:223230, out-dez, 1991

Tabela 2 - Total de amostras, número de rotavírus e respectivo percentual por faixa etária, em crianças com diarréia aguda, Brasilia, Distrito Federal - maio de 1986 a abril de 1990.

\begin{tabular}{|c|c|c|c|c|c|}
\hline \multirow{2}{*}{\multicolumn{3}{|c|}{$\begin{array}{c}\text { Faixa Etária } \\
\text { (Meses) }\end{array}$}} & \multirow[t]{2}{*}{ Amostras } & \multicolumn{2}{|c|}{ Rotavírus } \\
\hline & & & & $\mathrm{N}^{\circ}$ & $\%$ \\
\hline 0 & a & 6 & 195 & 21 & 10,77 \\
\hline 6 & $\mathbf{a}$ & 12 & 201 & 50 & 24,87 \\
\hline 12 & $\mathbf{a}$ & 24 & 134 & 41 & 30,59 \\
\hline 24 & $\mathbf{a}$ & 48 & 53 & 6 & 11,32 \\
\hline 48 & $\mathbf{a}$ & 72 & 24 & 5 & 20,83 \\
\hline
\end{tabular}

A eficiência na deteç̧ão de rotavírus foi comparada através das técnicas de PAGE e EIARA. Houve concordância em $99 \%$ das amostras analisadas; duas mostraram-se positivas apenas na técnica de PAGE e uma foi positiva apenas na técnica de EIARA.

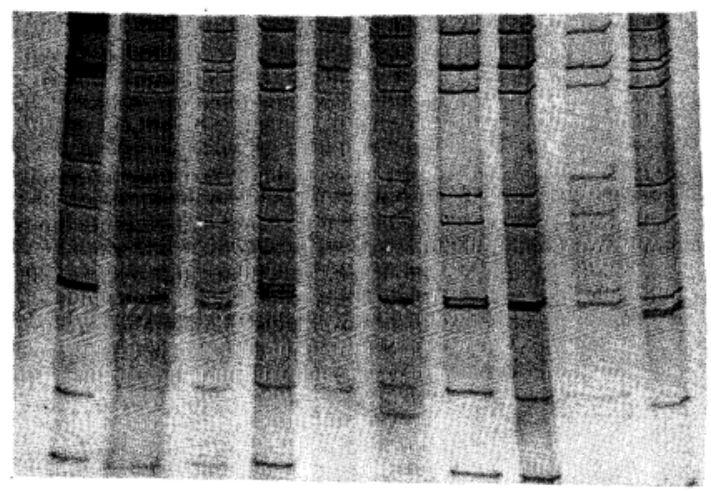

Figura 2 - Diferentes tipos de eletroforéticos de rotavírus detectados em Brasília, Distrito Federal - maio de 1986 a abril de 1990.

\section{DISCUSSÃO}

O genoma dos rotavírus consiste de 11 segmentos de RNA de fita dupla que podem ser separados em função do seu peso molecular, através da técnica de PAGE. A grande maioria dos rotavírus detectados através dessa técnica, pertencia ao subgrupo $\Pi(87,00 \%)$, mostrando que no Distrito Federal, esses vírus são mais comuns do que os dos subgrupo I. Essa observação também foi feita por outros autores tanto no Brasil ${ }^{1022}$ como em outras partes do mundo ${ }^{24}{ }^{27}$. O encontro de 23 diferentes tipos eletroforéticos, revelou uma grande diversidade genética entre os rotavírus circulantes no Distrito Federal. Em uma amostra foi observado um padrão eletroforético incomum, sendo detectados mais de 11 segmentos de RNA. Achados como esse já foram relatados $^{38}$ e têm sugerido a possibilidade de infecções simultâneas ou sequenciais por mais de um tipo eletroforético, ou modificações do tamanho do RNA durante a infecção $0^{28}$.

Os rotavírus foram detectados em $20,27 \%$ das amostras diarréicas analisadas. Ao contrário, a análise do grupo controle constituído de crianças sadias, não revelou a presença de rotavírus, mostrando que portadores assintomáticos não são comumente encontrados. No grupo de crianças internadas por outras causas que não diarréia, os rotavínus foram detectados em $7,80 \%$ das amostras. Infecções nosocomiais por rotavírus têm sido relatadas $^{14}{ }^{23}$ e podem estar relacionadas com os casos positivos observados nesse grupo de crianças.

Crianças de todas as faixas etárias estudadas mostraram-se suscetíveis às infecções por rotavírus. Entretanto, foram observadas diferenças entre as diversas faixas estudadas. A maioria das crianças incluídas no estudo pertencia à faixa etária de 0 a 12 meses $(65,23 \%)$, porém, a proporção de casos 
Teixeira JMS, Figueiredo RB, Santos HMP, Ferreira MNR, Câmara GNNL. Aspectos epidemiológicos das infecções por rotavirus no Distrito Federal, Brasil. Revista da Sociedade Brasileira de Medicina Tropical 24:223230, out-dez, 1991

positivos em relação ao total de amostras por faixa etária, foi significativamente maior entre crianças de 12 a 24 meses do que entre crianças de 0 a 12 meses $\left(x^{2}=10,41\right)$. Dentro da faixa etária de 0 a 12 meses foi constatada uma diferença significativa entre as faixas de 0 a 6 meses e de 6 a 12 meses $\left(x^{2}=14,36\right)$, sendo a positividade para rotavírus maior na faixa de 6 a 12 meses. A menor frequência de infecções por rotavírus em crianças menores de 6 meses, pode estar relacionada com o papel protetor conferido pelos anticorpos transferidos passivamente da mãe para a criança. Esses anticorpos entretanto, tendem a desaparecer após os três meses de vida ${ }^{15}$. Os anticorpos presentes no leite materno também devem exercer um importante papel protetor contra as infecções por rotavírus ${ }^{34}$, principalmente durante os primeiros seis meses de vida, período em que a prática do aleitamento é realizada com mais frequência. Não houve diferença significativa entre as faixas etárias de 6 a 12 meses e de 12 a 24 meses $\left(\mathrm{x}^{2}=1,6\right)$. Nessas duas faixas concentra-se a grande maioria das crianças cujas amostras foram positivas para rotavírus $(73,98 \%)$. Esses dados são coerentes com os obtidos por Soenarto e $\mathrm{col}^{25}$ na Indonésia.

Variações nas frequências de infecções por rotavírus em função da época do ano têm sido relatadas tanto no Brasil ${ }^{13}$ como em outros países do mundo $^{1131}$. No Distrito Federal, durante os quatro anos de estudo, os mais altos índices de infecção ocorreram sempre entre maio e setembro, período de baixa pluviosidade. A análise estatística dos dados da Figura 1 revelou um alto índice de correlação $(r=0,94)$, entre percentual de rotavírus e precipitação pluviométrica, indicando uma forte tendência linear negativa entre essas variáveis. Os resultados mostram uma clara variação sazonal nas infecções por rotavírus no Distrito Federal, sendo essas infecções mais frequentes no período seco do ano. Observações semelhantes foram feitas por Suzuki e $\mathrm{col}^{31}$ no Equador e Guerrant e col$^{9}$ na região nordeste do Brasil.

Moe e Shirley ${ }^{20}$ estudaram a sobrevivência de rotavírus em fezes, sob condições experimentais controladas. Tanto a baixa quanto a alta umidade associadas à baixa temperatura mostraram um efeito favorável à sobrevivência dos vírus. Os autores sugeriram uma correlação entre as condições experimentais que favoreceram a sobrevivência dos rotavirus e as condições climáticas prevalentes quando a frequência do vírus é alta. Os dados obtidos no presente trabalho mostraram que os períodos de alta pluviosidade são menos favoráveis às infecções por rotavírus, tendo sido registrados baixos índices de infecção. A média de positividadenos meses chuvosos foi igual a $9,60 \%$ e no período seco $34,46 \%$, com picos que variaram entre 53,12 e $73,22 \%$. Esses picos também coincidiram com os meses de junho e julho, os mais frios do ano. Resultados semelhantes foram observados na cidade de Goiânia, $\mathrm{GO}^{3}$, distante aproximadamente $240 \mathrm{~km}$ de Brasília, Distrito Federal. Na Tabela 3 onde foram comparados os valores médios das médias mensais de temperatura mínima, precipitação pluviométrica e percentual de rotavírus, no período de maio de 1986 a abril de 1990, o modelo ajustado na regressão linear múltipla foi significativo $(F=38,94 ; F$ crítico $=4,26)$, indicando que baixas temperaturas em conjunto com a baixa pluviosidade podem contribuir para o aumento da frequência de rotavírus.

Em países de clima temperado tem sido demonstrado que as maiores incidências de gastroenterites por rotavírus ocorrem durante os meses mais frios ${ }^{112}$, fato também observado em alguns países tropicais ${ }^{132}$. Regiões onde a temperatura e a umidade relativa do ar variam pouco, não foram observadas variações sazonais significativas nas frequências de rotavírus durante 0 ano ${ }^{1625}$.

A baixa umidade do ar e a baixa temperatura devem exercer um papel fundamental na sobrevivência dos rotavírus no Distrito Federal, sendo portanto, fatores ambientais determinantes da sazonalidade das infecções nessa região.

Os rotavírus são excretados em grande número juntamente com as fezes, podendo ser detectados em esgotos e águas contaminadas com esgotos ${ }^{30}$. Esse achado sugere a possibilidade de transmissão desses vírus através da ingestão de água poluída por esgoto. No presente estudo foi observado que $60,97 \%$ e $68,29 \%$ das crianças positivas para rotavírus tinham, em suas residências, respectivamente, água e esgoto ligadosà rede pública, o que nos leva a supor que talvez a via fecal-oral não seja a única envolvida na transmissão dos vírus.

Moe e Harper ${ }^{19}$ demonstraram, em condições controladas de laboratório, que os rotavírus podem permanecer viáveis em pequenas partículas em suspensão no ar. Aerossóis contendo rotavírus 
Teixeira JMS, Figueiredo RB, Santos HMP, Ferreira MNR, Câmara GNNL. Aspectos epidemiológicos das infeç̧ões por rotavirus no Distrito Federal, Brasil. Revista da Sociedade Brasileira de Medicina Tropical 24:223230, out-dez, 1991

Tabela 3 - Quadro comparativo dos valores médios das médias mensais de precipitação pluviométrica (mm), temperatura mínima e percentual de rotavírus, Brasília, Distrito Federal, maio de 1986 a abril de 1990.

\section{Mês}

\section{Preciptação \\ $(\mathrm{mm})$}

Temperatura

$\left({ }^{\circ} \mathrm{C}\right)$
Rotavírus

$(\%)$

$\begin{array}{lrrr}\text { Janeiro } & 168,50 & 18,0 & 13,05 \\ \text { Fevereiro } & 222,70 & 17,8 & 11,76 \\ \text { Março } & 213,50 & 17,9 & 8,06 \\ \text { Abril } & 115,90 & 17,3 & 19,04 \\ \text { Maio } & 21,17 & 15,9 & 34,61 \\ \text { Junho } & 19,70 & 13,7 & 48,15 \\ \text { Julho } & 11,70 & 13,1 & 40,32 \\ \text { Agosto } & 27,45 & 15,0 & 27,27 \\ \text { Setembro } & 49,60 & 17,0 & 15,79 \\ \text { Outubro } & 134,95 & 17,8 & 10,77 \\ \text { Novembro } & 219,45 & 17,7 & 4,10 \\ \text { Dezembro } & 308,50 & 18,1 & 6,25\end{array}$

poderiam ser formados através da descarga de sanitários, irrigação por aspersão com água de esgoto e mesmo durante a troca de fraldas de crianças. Os vírus suspensos em pequenas gotas poderiam ser levados para outros locais pelas correntes de ar, podendo ser inalados e produzir uma infecção do trato respiratório. As secreções naso-faríngeas poderiam ser deglutidas e, uma vez no trato digestivo, poderiam desencadear o processo diarréico. Sintomas do trato respiratório superior foram observados em 42 das 100 crianças hospitalizadas com gastroenterites por rotavírus na Inglaterra. Entretanto, a análise do material de orofaringe, através da microscopia eletrônica, não revelou a presença de rotavírus ${ }^{4}$. No Distrito Federal, o aumento na frequência de gastroenterites por rotavírus no período seco, coincide com o aumento do número de casos de infecções respiratórias agudas atendidos nos pronto socorros infantis da região. É possível que a via respiratória esteja envolvida na transmissão das infecções por rotavírus no Distrito Federal, principalmente no período de baixa pluviosidade. Estudos devem ser realizados, uma vez que não existem provas concretas indicando a transmissão por essa via.

\section{SUMMARY}

Rotavirus testing was perfomed on fecal samples of 607 infants and young children aging from 0 to 6 years with acute diarrhoea between May 1986 and April 1990. Samples were analyzed by polyacrylamide gel electrophoresis (PAGE). Rotaviruses were detected in 123 samples (20.27\%); from those, 107 187.00\%) were classified as subgroup II (long profile). Rotaviruses were not detected in the control group of healhy children, but it were present in $7.80 \%$ of the children haspitalized for other causes but acute diarrhoea. Most of the children with rotavirus infection ranged from 6 to 24 months of age (73.98\%). The mean of positive cases during the rainny months (October to April) was of $9.60 \%$ and during the dry period was of $34.48 \%$. The highest values were 53.17 and $73.27 \%$ in June and July, the coldest months of the year.

Key-words: Rotavirus. Acute diarrhoea in infants. Epidemiology.

\section{AGRADECIMENTOS}

Ao Dr. Marcus José Viana Gadelha (in memorian), a Dra. Lenora Gandolfi Schmitz e ao Instituto Nacional de Meteorologia (INEMET). 
Teixeira JMS, Figueiredo RB, Santos HMP, Ferreira MNR, Câmara GNNL. Aspectos epidemiológicos das infecções por rotavírus no Distrito Federal, Brasil. Revista da Sociedade Brasileira de Medicina Tropical 24:223230, out-dez, 1991

\section{REFERÊNCIAS BIBLIOGRÁFICAS}

1. Azeredo RS, de Farias V, Leite JPG, Pereira HG, Schatzmayr HG, Suttmoller F, Vidal MNP, Torós $M$, Solberg P. Agentes virais associados a gastroenterites infantis no Rio de Janeiro. Boletim Epidemiológico XV:7-8, 1983.

2. Boulikas T, Hancock R. A highly sensitive technique for stainning DNA and RNA in polyacrylamide gels using silver. Journal of Biochemical and Biophysical Methods 5:219-228, 1981.

3. Cardoso DDP, Brito WMED, Martins RMB, Kitajima EW, Souza MPM, Barbosa AJ, Oliveira SA, Rascopi SB. Ocorrência de rotavírus e adenovírus em amostras fecais de crianças com gastrenterite, na cidade de Goiânia. Revista da Sociedade Brasileira de Medicina Tropical 22:67$71,1989$.

4. Carr ME, Donald G, McKendrick W, Spyridakis T. The clinical features of infantile gastroenteritis due to rotavirus. Scandinavian Journal of Infections Diseases 8:241-243, 1976.

5. Coiro JRR, Almeida Neto AJ, Heuser MCF, Vasconcelos VL, Bendati MMA. Pesquisa exploratória de rotavírus e gastroenterite aguda no Brasil. Jornal de Antibioticoterapia 1:1-3, 1984.

6. Davidson GP, Townley RRW, Bishop RF, Holmes IH, Ruck BJ. Importance of a new virus in acute sporadic enteritis in children. The Lancet 1:242245, 1975.

7. Esparza J, Torres BV, Piñero A, Carmona FO, Ilja RM. Rotaviruses in Venezuelan children with gastroenteritis. The American Journal of Tropical Medicine and Hygiene 26:148-151, 1977.

8. Evans DG, Olarte J, Dupont HL, Evans DJ, Galindo E, Portnoy BL, Conklin RH. Enteropathogens associated with pediatric diarrhoea in Mexico city. Journal of Pediatrics 91:65-68, 1977.

9. Guerrant RL, Dirchoff LV, Shields DS, Nations MK, Leslie J, Souza MA, Araújo JG, Correia LL, Saner KT, McClelland KE, Towbridge FL, Hughes JM. Prospective study of diarrhoeae illness in northeastern Brazil: patterns of disease, nutritional infanct, etiologies, and risk factors. Journal of Infections Diseases 148:986-997, 1983.

10. Houly CAP, Uchoa MMM, Zaidan AME, GomesNeto A, De-Oliveira FM, Athayde MAG, Almeida MFLM, Pereira HG. Electrophoretic study of the genome of human rotavirus from Maceió, Brazil. Brazilian Journal of Medical and Biological Research 19:33-37, 1986.

11. Kapikian AZ, Kim HW, Wyatt RG, Gline WL, Arrobio JO, Brandt CD, Rodriguez WJ, Sack DA,
Chanock RM, Parrortt RH. Human reovirus-like agent as the major pathogen associated with "winter" gastroenteritis in hospitalized infants and young children. The New England Journal of Medicine 294:965-972, 1976.

12. Konno T, Suzuki H, Imai H, Kutsuzawa $T$, Ighida N, Katsushima N, Sakamoto M, Kitaoka S, Tsuboi $\mathbf{R}$, Adachi $\mathbf{M}$. A long term survey of rotavirus infection in japanese children with acute gastroenteritis. Journal of Infectious Diseases 138:569-576, 1978.

13. LaemmliOK. Cleavage of structural proteins during the assembly of the head of bacteriophage TS. Nature 227:680-685, 1970.

14. Lee FJE, Mindorff CM, Gold R, Petric M. The incidence of viral associated diarrhoeae after admission to a pediatric hospital. American Journal of Epidemiology 131:711-718, 1990.

15. Linhares AC, Melo VR, Mascarenhas JDP, Gabbay YB, Freitas RB. Pattern of acquisition of rotavirus antibody in children followed up from birth to the age of three years. Revista da Sociedade Brasileira de Medicina Tropical 22:25-29, 1989.

16. Linhares AC, Monção HC, Gabbay YB, Araújo VLC, Serruya AC, Loureiro ECB. Acute diarrhoea associated with rotavirus among children living in Belém, Brazil. Transations of the Royal Society of Tropical Medicine and Hygiene 77:384-390, 1983.

17. Lourenco MH, Nicolas JC, Cotren J, ScherT R, Bricout F. Study of human rotavirus genome by electrophoresis: attempt of classification among strains isolated in France. Annals of Virology (Instituto Pasteur) 132:161-173, 1981.

18. Mclean M, Brennan R, Hughes JM, Korzeniowski OM, Souza MA, Araujo JG, Benevides TM, Guerrant RL. Etiologia de la diarrea infantil y terapia de rehidratacion oral en el nordeste do Brasil. Boletín de la Oficina Sanitaria Panamericana 92:405-417, 1982.

19. Moe K, Harper GJ. The effect of relative humidity and temperature on the survival of bovine rotavirus in aerosol. Archives of Virology 76:211-216, 1983.

20. Moe K, Shirley JA. The effects of relative humidity and temperature on the survival of human rotavirus in faeces. Archives of Virology 72:179-186, 1982.

21. Pereira HG, Azeredo RS, Leite JPG, Andrade ZP, Castro LA. A combined enzyme immunoassay for rotavirus and adenovirus (EIARA). Journal of Virological Methods 10:21-28, 1985.

22. Pereira HG, Azeredo RS, Leite JPG, Candeias JAN, Racz ML, Linhares AC, Gabbay YR, Trabulsi 
Teixeira JMS, Figueiredo RB, Santos HMP, Ferreira MNR, Câmara GNNL. Aspectos epidemiológicos das infecções por rotavírus no Distrito Federal, Brasil. Revista da Sociedade Brasileira de Medicina Tropical 24:223230, out-dez, 1991

JR. Electrophoretic study of genome of human rotaviruses from Rio de Janeiro, São Paulo and Pará, Brazil. Journal of Hygiene 90:117-125, 1983.

23. Ringenbergs ML, Davidson GP, Spence J, Morris S. Prospective study of nosocomial rotavirus infection in a pediatric hospital. Australia Pediatric Journal 25:156-160, 1989.

24. RodgerSM, BishopRF, Birch C, Mclean B, Holmes IH. Molecular epidemiology of human rotavirus in Melborne, Australia, from 1973 to 1979 , as determined by eletrophoresis of genome ribonucleic acid. Journal of Clinical Microbiology 13:272-278, 1981.

25. Soenarto Y, Sebodo T, Ridho R, Alrasjid H, Rohde JE, Bugg HC, Barnes GL, Bishop RF. Acute diarrhoea and rotavirus infection in newborn babies and children in Yogyakarta, Indonesia, from June 1978 to June 1979. Journal of Clinical Microbiology 14:123-129, 1981.

26. Soenarto Y, Sebodo T, Suryantoro P, Krisnomurti, Haksohusodo S, Ilyas, Kusniyo, Ristanto, Romas MA, Noerhajati, Muswiroh S, Rohde JE, Ryan NJ, Luke RKJ, Bomes GL, Bishop RF. Bacteria, parasitic agents and rotaviruses associated with acute diarthoea in hospital in patient Indonesian children. Transations of the Royal Society of Tropical Medicine and Hygiene 77:724-730, 1983.

27. Spencer E, Avendaño F, Araya M. Caracteristics and analysis of electropherotypes of human rotavirus isolated in Chile. The Journal of Infectious Diseases 148:41-48, 1983.

28. Spencer EG, Avendaño LF, García BI. Analysis of human rotavirus mixed electropherotypes. Infectio:and Immunity 39:569-574, 1983.

29. Spencer HC, Wells JG, Gary W, Sondy J, Puhr ND, Feldman RA. Diarrhea in a non-hospitalized rural salvadoran population: the role of enterotoxigenic Escherichia coli and rotavirus. The American Journal of Tropical Medicine and Hygiene 29:246-253, 1980.

30. Steinmann J. Detection of rotavirus in sewage. Applied and Environmental Microbiology 41:10431045, 1981.

31. Suzuki H, Amano Y, Kinebuchi H, Vera EG, Davila A, Lopez J, Gustabo R, Konno T, Ishida N. Rotavirus infection in children with acute gastroenteritis in Equador. The American Journal of Tropical Medicine and Hygiene 30:293-294, 1981.

32. Torres BV, Ilja RM, Esparza J. Epidemiological aspects of rotavirus infection in hospitalized Venezuelan children with gastroenteritis. The American Journal of Tropical Medicine and Hygiene 27:567-572, 1978.

33. White L, Perez I, Perez M, Urbina G, Greenberg H, Kapikian $A Z$, Flores $G$. Relative frequency of rotavirus subgroups $I$ and II in Venezuelen children with gastroenteritis as assayed with monoclonal antibodies. Journal of Clinical Microbiobgy 19:516$520,1984$.

34. Yolken RH, Wyatt RG, Mata L, Umutia IJ, Garcia B, ChanockRM, Kapikian AZ. Secretory antibody directed against rotavirus in human milk: measurement by means of enzyme-linked immunosorber assay. Joumal of Pediatrics 93:916-921, 1978. 